\title{
O ensino por investigação como campo conceitual na teoria de Vergnaud
}

\section{Inquiry teaching as conceptual fields in Vergnaud's theory}

DOI: $10.46814 /$ lajdv2n5-007

Recebimento dos originais: 10/07/2020

Aceitação para publicação: 30/08/2020

\author{
Santer Alvares de Matos \\ Centro Pedagógico e Programa de Pós-graduação em Educação da Faculdade de Educação da \\ Universidade Federal de Minas Gerais \\ E-mail: santer@ufmg.br \\ Carmen Maria de Caro Martins \\ Colégio Técnico e Programa de Pós-graduação em Educação da Faculdade de Educação da \\ Universidade Federal de Minas Gerais \\ E-mail: carmendecaro@ufmg.br
}

\section{RESUMO}

Neste trabalho, apresentamos resultados de uma pesquisa maior que tem como objetivo investigar o impacto de um curso de especialização em Ensino de Ciências na prática docente. Apresentamos aqui uma possibilidade de compreender o ensino por investigação como campo conceitual à luz da teoria de Vergnaud. O trabalho associa o conceito de ensino por investigação aos principais conceitos da Teoria dos Campos Conceituais. Investiga-se, ainda, uma professora em formação continuada a fim de se analisar a evolução da compreensão dessa professora sobre ensino por investigação à luz da Teoria dos Campos Conceituais. Os resultados contribuem com a possibilidade de se compreender o conceito de ensino por investigação como campo conceitual e também apontam para uma evolução na compreensão do conceito de ensino por investigação da professora participante da pesquisa.

Palavras-chave: Ensino por investigação, Teoria dos Campos Conceituais, Formação Continuada.

\begin{abstract}
In this paper, we present results of a larger research which aims to investigate the impact of a graduate course in Science Teaching. Here, we present an opportunity to understand the inquiry teaching as conceptual field in Vergnaud's theory. This research associates the concept of inquiry teaching with the main concepts of the Theory of Conceptual Fields. It still examines a teacher in continuous formation program to analyze the comprehension evolution by inquiry teaching in Theory of Conceptual Fields. The results contribute to the possibility of understanding the concept of inquiry teaching as the conceptual field. They also pointed to a comprehension evolution of teacher's concept of inquiry teaching.
\end{abstract}

Keywords: Inquiry Teaching, Theory of Conceptual Fields, Teacher's Continuing Formation. 


\section{INTRODUÇÃO}

Esta proposta de pesquisa se insere na temática de formação continuada de professores de Ciências da Natureza, sendo fruto das vivências, observações e leituras de um dos autores como professor-pesquisador no curso de Ensino de Ciências por Investigação (ENCI).

O ENCI é um curso de especialização semipresencial, desenvolvido e ofertado pelo Centro de Ensino de Ciências e Matemática (CECIMIG) da Faculdade de Educação da UFMG, e tem como objetivo a qualificação e a atualização de docentes, visando à melhoria do Ensino de Ciências na Educação Básica, a partir da formação continuada e reflexiva. O curso é ofertado pelo CECIMIG desde 2005 e está, atualmente, na quarta versão.

O ensino por investigação é o alicerce de todo o ENCI. Um dos objetivos do curso é embasar os professores-cursistas do que seja uma atividade investigativa e sua importância para o ensino de Ciências.

Pesquisas recentes (SÁ et al., 2007; SÁ, 2009) indicam que o curso estaria impactando o modo como os professores cursistas interagem com seus estudantes em atividades de sala de aula. Por outro lado, assim como Sá et al. (2009), temos verificado problemas na concepção de ensino por investigação após a conclusão do ENCI. Assim, há a necessidade de contínuas pesquisas que investiguem a ocorrência das transformações na prática docente, o momento no qual ocorre e, principalmente, como ocorre. A formação continuada pode ser um caminho que propicie reflexões sobre a prática docente de modo a possibilitar um aprendizado mais significativo.

A partir das observações e dos questionamentos vivenciados durante o curso de especialização, da ausência de uma definição para a ideia de "ensino por investigação" e da necessidade crescente de pesquisas na área, propomos a presente pesquisa. O trabalho aqui apresentado se insere em uma pesquisa maior, que tem o objetivo de investigar o impacto que o curso de especialização em Ensino de Ciências por Investigação tem na prática docente dos professores que dele participam.

Nesta pesquisa, submetemos à comunidade que pesquisa o ensino de Ciências por investigação uma possibilidade de compreender essa abordagem como um campo conceitual na teoria de Vergnaud. Assim, propomos a utilização da Teoria dos Campos Conceituais como referencial teórico e metodológico para o trabalho que se realizará a posteriori. Este trabalho busca investigar como a Teoria dos Campos Conceituais de Vergnaud poderia contribuir para a compreensão do ensino por investigação.

Assim sendo, a relevância desta pesquisa se justifica por se tratar de um trabalho diferenciado no campo de estudo na formação de professores, focando na possiblidade de compreender o ensino 
por investigação por meio de um referencial ainda não explorado nesta perspectiva, trazendo, desta maneira, contribuições ímpares para a compreensão do ensino por investigação e para a área de pesquisa em Ensino de Ciências.

\section{REFERENCIAL TEÓRICO E METODOLÓGICO}

\subsection{TEORIA DOS CAMPOS CONCEITUAIS}

A Teoria dos Campos Conceituais, proposta por Gérard Vergnaud, é uma teoria cognitivista que objetiva apresentar-se como referencial "mais frutífero do que o piagetiano ao estudo do desenvolvimento cognitivo e da aprendizagem de competências complexas, [...] levando em conta os próprios conteúdos do conhecimento e a análise conceitual de seu domínio.” (MOREIRA, 2002, p.8).

O foco piagetiano de sujeito epistêmico é redirecionado, na Teoria dos Campos Conceituais, para o sujeito em situação, ou seja, o foco passa a ser a situação como desencadeadora da compreensão do conceito (CARVALHO JR., AGUIAR JR., 2008). Assim, busca-se compreender como o sujeito aprende a partir de situações e de problemas a resolver, sendo um processo lento e gradual (VERGNAUD, 1990).

Para Vergnaud (VERGNAUD apud MOREIRA, 2002, p.9), os campos conceituais representam um conjunto de situações e de problemas cujo domínio requer "conceitos, procedimentos e representações de tipos diferentes, mas intimamente relacionados.".

Vergnaud apresenta três razões para que se utilize o conceito de campo conceitual na análise da obtenção de conhecimento. Primeiramente, propõe a ideia de que um conceito não se forma a partir de um só tipo de situação. Em segundo lugar, propõe que uma situação não se analisa com um só conceito. Essas duas primeiras razões valorizam a visão integradora do conhecimento. Em terceiro, propõe que a construção e a apropriação de todas as propriedades de um conceito ou de uma situação é um processo longo, promovido pela maturidade e pela experiência, durante a vivência de situações diversas (VERGNAUD apud MOREIRA, 2002).

O conceito, na Teoria dos Campos Conceituais, constitui-se por um conjunto de três elementos: a situação (S), o invariante (I) e as representações simbólicas (R).

Quadro 1 - O conceito na Teoria dos Campos Conceituais de Vergnaud

\begin{tabular}{|c|c|c|}
\hline \multicolumn{3}{|c|}{ CONCEITO } \\
\hline SITUAÇÕES (S) & INVARIANTES (I) & $\begin{array}{c}\text { REPRESENTAÇÕES } \\
\text { SIMBÓLICAS (R) }\end{array}$ \\
\hline $\begin{array}{c}\text { As situações (S) são tarefas } \\
\text { responsáveis por dar sentido ao }\end{array}$ & $\begin{array}{c}\text { As invariantes (I) são as } \\
\text { reconhecidas e utilizadas pelos }\end{array}$ & $\begin{array}{c}\text { As representações simbólicas (R) } \\
\text { são representações das situações e }\end{array}$ \\
\hline
\end{tabular}


conceito, isto é, um conceito tornase significativo através de uma variedade de situações.

Representam o referente do conceito. A entrada em um campo conceitual ocorre por meio das situações. sujeitos para analisar e dominar as situações. Representam a operacionalidade e o significado dos conceitos.

Adaptado a partir de Carvalho Jr., Aguiar Jr. (2008); Moreira (2002); Sousa e Fávero (2002)

Os invariantes do comportamento para uma determinada classe de situações são organizados pelos esquemas. Moreira (2002, p.12) destaca que a noção de esquema é, para Vergnaud, a maior contribuição de Piaget e é entendida como "a organização invariante do comportamento para uma determinada classe de situações”. É nos esquemas que o conhecimento-em-situação se operacionaliza.

Nos esquemas, estão os invariantes operatórios que fazem a articulação da teoria com a prática, isto é, os invariantes operatórios representam o conhecimento-em-ação. O conhecimento-emação é constituído pelo teorema-em-ação e pelo conceito-em-ação (MOREIRA, 2002).

Teorema-em-ação é uma proposição considerada como verdadeira sobre o real. Conceito-emação é uma categoria de pensamento considerada como pertinente, relevante. Existe uma relação dialética entre conceitos-em-ação e teoremas-em-ação e ambos podem evoluir para conceitos e teoremas explícitos e válidos. O ensino deve buscar contribuir para que essa evolução do conhecimento-em-ação de fato ocorra, mesmo que demore muito tempo (MOREIRA, 2002; SOUSA E FÁVERO, 2002).

\subsection{O ENSINO DE CIÊNCIAS POR INVESTIGAÇÃO}

O ensino de Ciências por investigação está no centro das discussões do Ensino de Ciências nas últimas décadas, representando o princípio central dos Parâmetros Curriculares Nacionais de Ensino de Ciências (NRC, 2000) e do Projeto 2061: Ciências para todos (AAAS, 1989) dos norteamericanos.

No entanto, a definição do que seja ensino por investigação não é consensual entre os pesquisadores da área de ensino de Ciências. Segundo Sá et al. (2007, p.2), não há uma definição clara do que seja ensino por investigação, mesmo onde tal proposta "já está bem consolidada, como é o caso dos Estados Unidos, falta uma definição clara do conceito de ensino por investigação”.

Entre os pesquisadores, o que se verifica é a existência de uma polissemia em relação ao sentido do termo investigação, bem como de inúmeras perspectivas diferentes de ensino (GRANDY e DUSCHL, 2007; ANDERSON, 2002). Alguns pesquisadores compreendem o ensino por 
investigação como o que mais se aproxima da atividade conduzida por cientistas em suas práticas profissionais (CHINN e MALHOTRA, 2002). Para outros, porém, ensinar por investigação consiste em um tipo especifico de trabalho prático realizado em aulas de Ciências (TAMIR, 1990). Gott e Duggan (1995), assim como outros pesquisadores, consideram o ensino por investigação como uma estratégia metodológica que se centra na resolução de problemas e no exercício da autonomia. Assim, a conceitualização de ensino por investigação representa um termo, no sentido clássico, impossível de ser realizada (SÁ et, al., 2007). Entretanto, a palavra “investigação" pode nos auxiliar na compreensão do que venha a ser uma atividade investigativa. No Dicionário Eletrônico Houaiss, encontram-se as seguintes definições para "investigação": "estudo ou série de estudos geralmente extensos e rigorosos sobre alguma coisa" e "conjunto de atividades e diligências tomadas com o objetivo de esclarecer fatos". Nessa perspectiva, as atividades investigativas são aquelas nas quais os estudantes se envolvam em questões de caráter científico, priorizando a localização de evidências para responder a questões e para formular explicações, sendo capazes de avaliarem explicações em relação a teorias diversas, justificando e comunicando suas explicações (NRC, 2000; CARVALHO, 2004; MUNFORD e LIMA, 2007).

A ausência de um conceito clássico não é um problema para o ensino por investigação. Entretanto, Munford e Lima (2007) chamam a atenção para duas concepções problemáticas: primeiramente, falam sobre a frequente associação entre atividades investigativas e práticas experimentais e, em seguida, comentam sobre a vinculação automática entre ensino por investigação e atividades ditas "abertas", nas quais os alunos têm autonomia para escolher questões, determinar procedimentos e decidir como analisar seus resultados. Concepções problemáticas como as descritas deturpam a compreensão do que seja a autêntica atividade investigativa (MUNFORD e LIMA, 2007). Ainda segundo Munford e Lima (2007), em se tratando das atividades investigativas, o importante é conceber a possibilidade de múltiplas configurações com diferentes níveis de direcionamento por parte do (a) professor (a). Articulando com a afirmação de Munford e Lima (2007), Sa et al. (2007) exemplificaram algumas atividades que apresentam potencial para expressar o viés investigativo, tais como: atividades práticas e teóricas, trabalho com banco de dados, avaliação de evidências e atividades de simulação.

A maioria dos pesquisadores na área afirma que a problematização pode representar o início da atividade investigativa (MUNFORD e LIMA, 2007). Assim, o que caracteriza uma atividade como sendo investigativa não é a identidade da própria atividade, mas a sequência didática. Dessa maneira, uma aula prática pode ou não ser considerada investigativa. Munford e Lima (2007) chamam a atenção de que uma atividade experimental, muitas vezes, pode não apresentar 
características essenciais de uma atividade investigativa, não sendo considerada como tal. A partir de uma pesquisa realizada com professores e tutores de um curso de especialização em Ensino de Ciências por Investigação, Sá et al. (2007) propuseram que atividades investigativas devem possuir como características: construir problemas, valorizar o debate e a argumentação, propiciar a obtenção e avaliação de evidências, aplicar e avaliar teorias científicas e permitir múltiplas interpretações.

As atividades investigativas como estratégias de ensino podem potencialmente contribuir para que o ensino de Ciências ocorra de modo "interativo, dialógico e capaz de persuadir os alunos a compreender a validade das explicações científicas dentro de certos contextos. Desse modo, superarse-ia um ensino de Ciências centrado em discursos autoritários, prescritivos e dogmáticos" (SÁ, 2009, 5p.). Em decorrência, verifica-se uma tendência contemporânea do ensino de Ciências ser realizado por atividades investigativas. Segundo os Parâmetros Curriculares Nacionais de Ciências dos Estados Unidos (NRC, 2000), a investigação é uma atividade motivada pela curiosidade natural e tipicamente humana. A partir disto, os professores e, especificamente os de Ciências, devem sustentar tal curiosidade nos alunos, auxiliando-os a desenvolver habilidades relacionadas à investigação científica (CHINN e MALHOTRA, 2002). Segundo Lima e Maués (2006), os alunos que são colocados em processos investigativos, envolvem-se com a sua aprendizagem, constroem questões, levantam hipóteses, analisam evidências e comunicam os seus resultados. Em um ambiente de ensino e aprendizagem baseado na investigação, os estudantes e os professores compartilham a responsabilidade de aprender e de colaborar com a construção do conhecimento. Os professores deixam de ser os únicos a fornecer conhecimento e os estudantes deixam de desempenhar papéis passivos de meros receptores de informação.

Embora possa se perceber um interesse crescente pelo tema entre pesquisadores e educadores da área de Ciências sobre o ensino por investigação (AZEVEDO, 2004; CARVALHO, 2004; SÁ et al., 2007; MUNFORD e LIMA, 2007, SÁ et al., 2009), o número de artigos publicados ainda é pouco significativo, o que dificulta a discussão sobre o tema e, enfim, a sua compreensão.

Devido ao fato de o ensino por investigação uma abordagem ser de difícil compreensão, é importante que os professores, para compreenderem e transformarem sua prática, participem de cursos de formação continuada que enfoquem o tema. Por meio dos cursos de formação continuada, os professores podem comparar suas práticas com aquelas que lhes são apresentadas e isto possibilita uma reflexão sobre a própria prática docente. Assim, o professor assume sua prática a partir do significado que ele mesmo atribui a ela, ou seja, as situações pelas quais o professor irá passar podem contribuir para a compreensão do que seja o ensino por investigação (GOUVÊA, 1995). Desse modo, 
torna-se fundamental compreender um pouco da importância do processo de formação continuada no exercício da profissão de professor.

\subsection{FORMAÇÃO CONTINUADA}

A reflexão da prática pedagógica deve ser privilegiada nos cursos de formação continuada e, nesse contexto, o professor deve assumir o papel central da formação, sendo ativo no processo de construção e de transformação da própria prática pedagógica. Assim, ampliam-se as possibilidades de rompimento com os tradicionais padrões de cursos de formação continuada (SANTOS et al., 2006).

Os programas de formação continuada realizados no Brasil e, em especial na linha de Ciências da Natureza, possuem a limitação de serem cursos de atualização ou de capacitação, geralmente de carga-horária reduzida, nos quais não se rompe com a racionalidade técnica dos professores dessa área específica (MARANDINO, 1997). Entretanto, segundo Rosa et al. (2003), o Brasil passa por um período diferenciado no que se relaciona às reformas curriculares e à formação dos professores.

Santarosa (2005) afirma que os cursos de formação continuada à distância estão se consolidando no mundo inteiro, impactando, significativamente o processo de ensino e aprendizagem, apresentando novas perspectivas de acesso ao conhecimento e à formação, não se limitando no tempo e no espaço, possibilitando o desenvolvimento e gerenciamento da autonomia e reforçando o professor como sujeito do próprio processo de formação.

Os cursos de formação continuada de professores devem enfatizar o aspecto formador da educação e não apenas a assimilação de conteúdos. Assim, o professor terá a oportunidade de refletir sobre os processos de ensino e aprendizagem e perceber que eles não se resumem à repetição de uma aula, sempre com as mesmas estratégias, mas à necessidade de que o aluno seja capaz de modificar suas concepções sobre o mundo natural. O professor deve desenvolver estratégias que oportunizem ao aluno romper com os conceitos prévios errôneos, fortalecendo os cientificamente corretos (LÔBO NETO, 2001).

Estas concepções inadequadas de ciência e de conhecimento científico e a sua inserção no espaço escolar, através das aulas de ciências são, em parte, resultantes da ausência de uma abordagem histórica, epistemológica e sociológica da ciência, nos cursos de formação de professores. O que se observa nestes cursos é uma ênfase excessiva sobre os conceitos científicos, em detrimento dos processos de produção da ciência. Desta forma, torna-se necessário repensar o ensino de ciências e a formação do professor buscando inserir os conhecimentos científicos, pedagógico e escolar dentro de referenciais epistemológicos que rompem com a filosofia positivista e sua concepção de verdade científica e mostrem o caráter histórico na produção do conhecimento científico contribuindo, assim, para uma imagem mais adequada da ciência. (LÔBO NETO, 2001) 
O processo de formação continuada permite que o professor seja capaz de modificar a sua própria prática docente e, se tornar um agente transformador do meio ao qual está inserido (TARDIF, 2002). Ainda para Tardif (2002), na prática docente, o professor externaliza e evidencia suas crenças, valores e concepções. Dessa maneira, a formação continuada pode contribuir para a ampliação das concepções científicas e metodológicas, possibilitando uma alteração na prática docente do professor e, assim, atingindo aos alunos.

O professor formado na perspectiva proposta pelo curso no qual a presente pesquisa foi desenvolvida utiliza metodologias que rompem com o modelo tradicional de ensino de Ciências. Na perspectiva problematizadora do ensino por investigação, o professor é o mediador do processo, vivenciando e refletindo sobre várias situações investigativas, fornecendo subsídios para que os professores-cursistas consigam assimilar o ensino por investigação (LÔBO NETO, 2001).

A formação continuada é um caminho possível para que o professor busque as mudanças necessárias à atividade docente, favorecendo a prática eficaz capaz de tornar o aprendizado dos alunos mais significativo.

\section{METODOLOGIA}

A pesquisa foi desenvolvida seguindo duas frentes metodológicas. A primeira teve o objetivo de analisar o ensino por investigação como campo conceitual. A segunda teve o fim de analisar a evolução da ideia de ensino por investigação na perspectiva da Teoria dos Campos Conceituais de Vergnaud.

Para pesquisar o ensino por investigação como campo conceitual, associamos e analisamos, após leituras das referências, as estruturas da Teoria dos Campos Conceituais com as características que definem uma atividade como sendo investigativa. Assim, objetivamos pesquisar se o ensino por investigação poderia ser um conceito segundo a Teoria dos Campos Conceituais proposta por Vergnaud.

Para pesquisar a evolução do ensino por investigação na perspectiva da Teoria dos Campos Conceituais, foram analisadas as respostas de uma professora no curso de especialização em Ensino de Ciências por Investigação (ENCI), ofertada pelo CECIMIG, em dois momentos distintos do curso. O primeiro logo no início do curso. Outro, após três semestres de curso.

O curso de especialização está na quarta edição, sendo realizado a distância com alguns encontros presenciais. Os professores-cursistas possuem área de formação inicial em Física, Química, Biologia e Ciências, estando em pleno exercício profissional. Assim, o curso objetiva a formação continuada e a atualização dos docentes, por meio da reflexão da própria prática pedagógica. 
A professora-cursista (aluna do curso de especialização, objeto desta pesquisa) está no terceiro módulo do curso, tendo cada módulo a duração de um semestre. A delimitação da amostra em uma professora se justifica na intencionalidade de analisar se a Teoria dos Campos Conceituais podem ajudar na compreensão da evolução do ensino por investigação. A escolha da professoracursista ocorreu com base em dois critérios. Alguns alunos (21 alunos) responderam a um questionário inicial sobre as concepções do ensino por investigação. No terceiro módulo, alguns desses alunos (cinco alunos) responderam novamente ao questionário. Desse universo de alunos, a professora-cursista foi sorteada para ter as respostas do questionário analisadas. Como a professora, ao término do terceiro semestre, já havia cursado as disciplinas obrigatórias, esperamos que ela já possuísse uma melhor compreensão do que seja o ensino por investigação. Fazendo uso das duas frentes metodológicas, buscamos investigar como a Teoria dos Campos Conceituais de Vergnaud poderia contribuir para a compreensão do ensino por investigação.

\section{RESULTADOS}

\subsection{ENSINO POR INVESTIGAÇÃO COMO CAMPO CONCEITUAL}

No presente trabalho, propomos entender o ensino por investigação como conceito na perspectiva da Teoria dos Campos Conceituais de Vergnaud. Assim, o ensino por investigação não possuiria um conceito clássico em consonância com as recentes pesquisas, mas se comportaria como campo conceitual na perspectiva teórica de Vergnaud.

Temos observado que os professores que participam do curso de especialização em Ensino de Ciências por Investigação (ENCI) têm, ao longo do curso, ampliado a compreensão do que seja ensinar por investigação. Entretanto, tal compreensão, mesmo ao término do curso, não ocorre na totalidade do conceito de ensino por investigação. Tal observação se alinha ao fato de que, para Vergnaud, o conhecimento organiza-se em campos conceituais cujo domínio ocorreria ao longo de um extenso período de tempo, mediante situações que favoreçam a aprendizagem. Tal evidência seria o primeiro indício de que o ensino de Ciências poderia ser compreendido como campo conceitual na perspectiva da teoria de Vergnaud.

O segundo indício está nas três justificativas que Vergnaud apresenta para que se utilize o conceito de campo conceitual:

(1) A compreensão conceitual do ensinar por investigação ocorre, como se tem observado no curso de especialização ENCI, através de várias situações. A diversidade de situações permite que os professores-cursistas possam testar o conceito de ensino por investigação em diferentes contextos, enriquecendo e ampliando o campo de compreensão do ensino por investigação; 
(2) Em uma situação que utiliza o ensino por investigação, não existe apenas tal conceito, mas também o de problematização, autonomia, evidências, argumentação, etc. Assim, verifica-se o alinhamento com a teoria de Vergnaud para a qual uma situação não se analisa com um só conceito. Quando os professores-cursistas trabalham conceitos estruturantes para um dado campo conceitual, está se favorecendo a compreensão do próprio campo quanto conceito;

(3) Mesmo após quase dois anos em contato com o ensino por investigação, ao término do curso, os professores-cursistas não demonstram um domínio total desse conceito, estando de acordo com a proposta de Vergnaud de que a apropriação de todas as propriedades de um conceito se dá ao longo de um extenso período de tempo.

Dessa maneira, observa-se que o ensino por investigação pode ser compreendido através de situações e de domínio de outros conceitos em um processo longo. Tais estruturas alinham-se às justificativas apresentadas por Vergnaud para que se utilize o conceito de campo conceitual.

O conceito, na Teoria dos Campos Conceituais, deve apresentar três conjuntos estruturadores: situação, invariantes e representações simbólicas.

$\mathrm{Na}$ determinação do ensino por investigação quanto campo conceitual, torna-se fundamental apresentar as situações, os invariantes e as representações simbólicas (Quadro 2).

Quadro 2 - O conceito de Ensino por Investigação na perspectiva da Teoria dos Campos Conceituais

\begin{tabular}{|c|c|c|c|}
\hline \multicolumn{4}{|c|}{ CONCEITO DE ENSINO POR INVESTIGAÇÃO } \\
\hline $\begin{array}{l}\text { Situações (tarefas) que envolvem o } \\
\text { conceito de Ensino por } \\
\text { Investigação }\end{array}$ & \begin{tabular}{llll} 
Invariantes & \multicolumn{2}{c}{ operatórios } & $\mathrm{q}$ \\
caracterizam & $\mathrm{o}$ & Ensino & $\mathrm{p}$ \\
Investigação & & & \\
\end{tabular} & $\begin{array}{l}\text { Representações simbólicas } \\
\text { Ensino por Investigação }\end{array}$ & \\
\hline $\begin{array}{l}\text { - Atividades práticas; } \\
\text { - Atividades teóricas; } \\
\text { - Atividades com filmes; } \\
\text { - Atividades com banco de dados; } \\
\text { - Atividades de avaliação de } \\
\text { evidências; } \\
\text { - Atividades de simulação. }\end{array}$ & $\begin{array}{l}\text { - } \text { Problematização; } \\
\text { - Debate e argumentação; } \\
\text { - } \text { Autonomia e heteronomia } \\
\text { - Obtenção e avaliação } \\
\text { evidências; } \\
\text { - Aplicação e avaliação } \\
\text { teorias científicas; } \\
\text { - Multiplicidade } \\
\text { interpretações. }\end{array}$ & $\begin{array}{l}\text { - Desafio } \rightarrow \text { Solução; } \\
\text { - Pergunta } \rightarrow \text { Hipóteses } \\
\text { Estratégias } \rightarrow \text { Conclusão; } \\
\text { - Problema } \rightarrow \quad \text { Debate } \\
\text { Conclusão. }\end{array}$ & $\rightarrow$ \\
\hline
\end{tabular}

Ao determinar se uma tarefa ocorre ou não na concepção de ensino por investigação, o professor-cursista estará operacionalizando invariantes que o auxiliará a caracterizar uma atividade como sendo ou não investigativa. Dessa maneira, o sentido de situação ocorre de acordo com duas ideias principais: variedade e história. Historicamente, a concepção de investigação que professores de Ciências possuem restringe-se a atividades práticas, experimentais. Tal concepção ocorre principalmente em função da formação inicial. À medida que o professor se depara com variadas 
tarefas (situações) que não sejam, necessariamente, práticas e consegue distinguir, através dos invariantes operatórios, quais são investigativas, a compreensão do conceito de ensino por investigação é ampliada. Quando o professor tenta expressar por meio de representações o que seja ensinar por investigação, algumas concepções se tornam evidentes, possibilitando a avaliação dos esquemas utilizados pelo professor e, consequentemente, a compreensão do campo conceitual.

Verificamos que o ensino por investigação, por apresentar os três conjuntos estruturadores do conceito, pode se alinhar à perspectiva da Teoria dos Campos Conceituais. Ao se considerar que uma situação se alinha ao campo conceitual de ensino por investigação, é importante analisar, nos esquemas utilizados pelos professores, os invariantes operatórios.

Os esquemas podem ser verificados nas justificativas utilizadas pelos professores para justificar o porquê de uma situação poder ser conceitualizada como investigativa ou não, ou seja, são nos esquemas que o conhecimento-em-situação se operacionaliza. Nos esquemas, encontram-se os invariantes operatórios (um dos conjuntos formadores do conceito) que fazem a articulação da teoria com a prática. Os invariantes operatórios representam o conhecimento-em-ação, isto é, o conceito e o teorema em ação. Caso haja uma evolução no conhecimento-em-situação, isto é, o aumento na explicitação dos conceitos e dos teoremas-em-ação pelos professores, haverá uma evolução no conceito de ensino por investigação.

Assim, para verificar se o ensino por investigação pode ser compreendido como campo conceitual, é fundamental a análise da evolução de um professor em relação ao que ele mesmo compreende como ensino por investigação.

\subsection{A EVOLUÇÃO DO CAMPO CONCEITUAL DE ENSINO POR INVESTIGAÇÃO}

Considerando que a intencionalidade era a de pesquisar o ensino por investigação como campo conceitual, torna-se fundamental compreender a evolução do conceito de ensino por investigação na perspectiva teórica de Vergnaud.

Para compreender a evolução do ensino por investigação como campo conceitual, serão analisadas as respostas dadas ao questionário inicial e ao final do terceiro módulo de uma professora em formação continuada do curso de especialização em Ensino de Ciências por Investigação. Assim, como Carvalho Jr.\& Aguiar Jr. (2008) e Brandão et al. (2010), optamos por não utilizar, como indicadores de progresso, as produções coletivas como as ocorridas nos fóruns das disciplinas cursadas pela professora-cursista.

Para manter a identidade da professora em sigilo, a identificaremos, a partir de agora, como Marta (nome fictício). Marta é licenciada em Ciências com habilitação em Biologia e está aposentada 
por tempo de serviço. Recentemente, ela voltou à sala de aula como professora de Ciências da Educação Infantil. Assim, pode-se afirmar que Marta possui vasta experiência em sala de aula de Ciências, embora não se possa fazer afirmação semelhante em relação às estratégias, conceitos e metodologias do ensino de Ciências, por razões de limitação da presente pesquisa. A seguir, apresentamos a expressão do conhecimento-em-ação nas respostas da professora Marta em dois momentos do curso: no primeiro e no último módulo. $\mathrm{O}$ espaço de tempo entre a resposta inicial e a final é de dezessete meses.

\begin{tabular}{|c|c|}
\hline Questão 01: & O que é ensinar Ciências por investigação? \\
\hline $\begin{array}{l}\text { Resposta } \\
\text { inicial: }\end{array}$ & 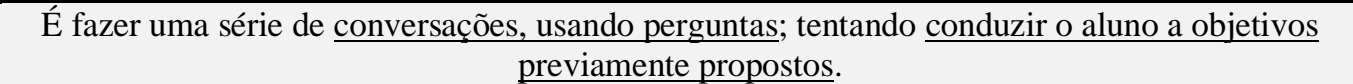 \\
\hline $\begin{array}{l}\text { Resposta } \\
\text { final: }\end{array}$ & $\begin{array}{l}\text { Ensinar ciências por investigação é problematizar um tema em sala de aula, proporcionar } \\
\text { discussões tentando entusiasmar a turma de tal modo que os alunos possam expor e trocar ideias } \\
\underline{\text { e vivências. }} \text { O professor deve envolver o aluno para que o mesmo tenha condições de formular } \\
\underline{\text { hipóteses e questionamentos, alcançando assim os propósitos objetivados no planejamento }} \\
\text { pedagógico. }\end{array}$ \\
\hline
\end{tabular}

Inicialmente, Marta não explicita nenhum teorema-em-ação. Os conceitos-em-ação de problematização são timidamente externalizados, já que não se pode afirmar que "conversações, usando perguntas" possam explicitar a problematização. Na resposta final, Marta apresenta o ensino por investigação como atividade problematizadora e dialógica, sendo um teorema-em-ação que depende da compreensão do que seja problematização, debate e argumentação. Outro teorema-emação que pode ser observado é o conhecimento prévio de “ideias e vivências". Há indícios da autonomia do aluno quando Marta afirma que os alunos devem "formular hipóteses $e$ questionamentos". Em ambas as etapas, verifica-se que o processo é guiado por um objetivo previamente planejado pela professora.

\begin{tabular}{c|c|}
\hline Questão 02: & O que caracteriza uma atividade como sendo investigativa? \\
\hline $\begin{array}{c}\text { Resposta } \\
\text { inicial: }\end{array}$ & $\begin{array}{c}\text { Uma atividade investigativa realiza explanações sobre assuntos a serem trabalhados, usando de } \\
\text { perguntas e observações em laboratório. O trabalho é finalizado ao serem tiradas as conclusões }\end{array}$ \\
\cline { 2 - 2 } $\begin{array}{c}\text { Resposta } \\
\text { final: }\end{array}$ & \begin{tabular}{c} 
Uerais. Resumindo uma prática laboratorial como atividade de ensino. \\
\cline { 2 - 2 }
\end{tabular}
\end{tabular}

A resposta inicial caracteriza a atividade investigativa como sendo uma aula prática. Nesse contexto, o conceito de ensino por investigação apresenta-se como atividade prática. Os conceitosem-ação que podem ser observados são os de perguntas e conclusões gerais. Fundamentando-se nos dois conceitos-em-ação e no resumo que a professora apresenta ao final, pode-se dizer que a 
representação simbólica para o ensino por investigação da professora seria: Ensino por investigação = atividade prática. A resposta posterior é mais objetiva e possui dois conceitos-em-ação: discurso (que poderia inferir em outros dois: debate e argumentação) e problematização. Assim, o teorema-em-ação seria o ensino por investigação apresentar a problematização e o debate e o argumento como características marcantes.

\begin{tabular}{|c|c|}
\hline Questão 03: & Qual a importância da investigação para o ensino de Ciências? \\
\hline $\begin{array}{l}\text { Resposta } \\
\text { inicial: }\end{array}$ & $\begin{array}{l}\text { A importância da investigação para o ensino das Ciências é o aprendizado através de situações } \\
\text { práticas e o incitamento à curiosidade; o que pode resultar em gosto pela busca do } \\
\underline{\text { conhecimento }} \text { e pelo uso da pesquisa. }\end{array}$ \\
\hline $\begin{array}{l}\text { Resposta } \\
\text { final: }\end{array}$ & $\begin{array}{l}\text { A investigação nas aulas de ciências é de suma importância, pois coloca o aluno no centro das } \\
\text { discussões e questionamentos. Leva-os a produzir intervenções lógicas e críticas, amplia suas } \\
\underline{\text { ideias e oportuniza o compartilhamento de suas vivências; objetivando assim a construção do }} \\
\text { seu próprio saber. }\end{array}$ \\
\hline
\end{tabular}

$\mathrm{Na}$ resposta inicial, o teorema-em-ação da professora é o de que a atividade investigativa é uma situação prática (experimental). O conceito-em-ação é o de atividade práticas, ou seja, aquela que se realiza na prática, um experimento. Observa-se que, incialmente, a existência de indícios de autonomia quando a professora fala na "busca do conhecimento e pelo uso da pesquisa". Posteriormente, a resposta apresenta a explicitação de vários conceitos-em-ação, destacando-se: discussões, questionamentos, lógicas e críticas. Observam-se, também, três teoremas-em-ação: o aluno como agente transformador do conhecimento (autonomia, foco no aluno), busca de evidências científicas a partir da observação do cotidiano e a elaboração de conclusões a partir da multiplicidade de interpretações das evidências científicas.

\begin{tabular}{|c|c|}
\hline Questão 04: & $\begin{array}{l}\text { ocê já realizou alguma atividade investigativa em sala de aula? Como foi? Qual (e só vale } \\
\text { ma) a principal característica da atividade realizada que a torna investigativa? }\end{array}$ \\
\hline $\begin{array}{l}\text { Resposta } \\
\text { inicial: }\end{array}$ & $\begin{array}{l}\text { Sim. Fizemos a observação no microscópio de um olho de gafanhoto, para melhor entender sua } \\
\text { estrutura. Foi uma festa, pois, os alunos ficaram muito entusiasmados e pediram para repetir a } \\
\text { experiência usando outros materiais. }\end{array}$ \\
\hline $\begin{array}{l}\text { Resposta } \\
\text { final: }\end{array}$ & $\begin{array}{l}\text { Sim, já realizei atividade investigativa em sala de aula. O que a tornou investigativa foi a } \\
\text { problematização do tema estudado. A proposta é analisar os rótulos dos produtos } \\
\text { industrializados. Iniciamos a proposta com o seguinte questionamento: Será que as pessoas ao } \\
\text { comprar os produtos alimentícios observam a sua validade? Os alunos pesquisaram sobre o } \\
\text { assunto, investigaram com seus pais e observaram os produtos industrializados de suas casas. } \\
\text { Depois levaram os rótulos para a sala de aula para serem analisados por toda a turma. A partir } \\
\text { dessa atividade, verificamos que muitas pessoas não têm o hábito de observar a validade dos } \\
\text { produtos comprados e poucas são as que verificam a validade dos mesmos. Considero que as } \\
\text { atividades investigativas devem ser levantadas através de discussões, questionamentos, } \\
\text { formulação de hipóteses, observação, oportunidade de vivenciar a situação, reflexão e } \\
\text { aproveitando todas as oportunidades que possibilitem a construção do conhecimento científico. }\end{array}$ \\
\hline
\end{tabular}

A resposta inicial reforça o teorema-em-ação de que a situação que caracteriza o ensino por 
investigação seja a atividade prática. Observa-se que, para a professora, a melhor atividade investigativa foi uma aula prática, laboratorial de observação do olho do gafanhoto. Como a professora não responde a principal característica da situação que a define como sendo investigativa, pressupõe-se que a situação prática seja a própria característica, reforçando o teorema-em-ação de que o ensino por investigação ocorra em situações práticas (experimentais). Por meio da resposta final, observa-se uma ampliação dos conceitos-em-ação (problematizar, questionar, investigar, pesquisar, observar, analisar, discutir, refletir e formular hipóteses). O teorema inicial também se modifica, pois a situação deixa de ser experimental (prática) e adquire um caráter investigativo de pesquisa. Assim, o teorema-em-ação principal é o de que o ensino por investigação pode ser evidenciado em outras situações que não sejam experimentais. Do mesmo modo, na resposta final, pode-se perceber uma evidente evolução no conceito de ensino por investigação.

\section{CONSIDERAÇÕES FINAIS}

Diante da ausência de consenso conceitual para o ensino por investigação, a Teoria dos Campos Conceituais apresenta-se como "novo" referencial para compreender o conceito ensino por investigação. Assim, tudo sinaliza que a estratégia de ensino por investigação pode ser compreendida como conceito na teoria de Vergnaud.

Os resultados da presente pesquisa possibilitam concluir que a Teoria dos Campos Conceituais pode se constituir como referencial de análise e de compreensão do conceito de ensino por investigação. Durante a formação continuada, a professora pesquisada apresentou uma ampliação da explicitação do conhecimento-em-ação sobre o ensino por investigação. Assim, sugerimos que a Teoria dos Campos Conceituais apresenta um potencial para se compreender a evolução do campo conceitual de ensino por investigação em professores.

Para a área de pesquisa, sugerimos um aprofundamento no estudo do conhecimento-em-ação, buscando-se investigar as atividades desenvolvidas pelos professores-cursistas no curso e a ampliação das investigações do ensino por investigação à luz da Teoria dos Campos Conceituais. Sugerimos, ainda, que outras estratégias de mediação pedagógica possam ser investigadas como conceitos na perspectiva teórica de Vergnaud. 


\section{REFERÊNCIAS}

AAAS. American Association for the Advancement of Science. (1989). "Science for all Americans: A Project 2061 report on literacy goals in science, mathematics, and technology". Washington, DC: Author. [Available online at: http://www.project2061.org/tools/sfaaol/sfaatoc.htm]

ANDERSON, R. D. Reforming Science Teaching: What Research says about Inquiry. Journal of Science Teacher Education, 13(1): 1-12, 2002

AZEVEDO, M.C.P.S. de. Ensino por Investigação: Problematizando as atividades em sala de Aula. In: Ensino de Ciências: Unindo a Pesquisa e a Prática. Organizado por Anna Maria Pessoa de Carvalho, Editora Thomson, 2004.

BRANDÃO, R.V.; ARAUJO, I.S.; VEIT, E.A. Concepções e dificuldades dos professores de Física no campo conceitual da modelagem científica, Revista Eletrónica de Enseñanza de las Ciencias, v.9, n.3, p-669-695, 2010.

CARVAlHO, A. M. P. (org). Ensino de Ciências: unindo a pesquisa e a prática. São Paulo: Pioneira Thompson Learning, 2004.

CARVALHO JR., G.D.; AGUIAR JR., O. Os campos conceituais de Vergnaud como ferramenta para o planejamento didático. Caderno Brasileiro de Ensino de Física, v.25, n.2, p. 207-227, 2008.

CHINN, C; MALHOTRA, B.A. (2002). Epistemologically authentic inquiry in schools: A theoretical framework for evaluating inquiry tasks. Science Education, 86:175-218.

GOTT, R. \& DUGGAN, S. Investigative Work in the Science Curriculum. Série: Developing Science and technology education. Open University Press, 1995.

GOUVEIA, M. S. F. Ensino de Ciências e Formação continuada de professores. Educação e Filosofia, 17(1) 227-257. Jan/Jun. 1995.

GRANDY, R. \& DUSCHIL, R. Reconsidering the Character and Role of Inquiry in School Science: Analysis of a Conference. Science\& Education, v.16, n.2 fevereiro, 2007.

LIMA, M.E.C.C. Maués, E. Uma releitura do papel da professora das séries iniciais no desenvolvimento e aprendizagem de ciências das crianças. Ensaio, v.8, n.2, p.161-175, 2006.

LÔBO NETO, F.J.S. Educação à distância: referências e trajetórias. Rio de Janeiro: Associação Brasileira de Tecnologia Educacional; Brasília: Plano Editora, 2001.

MARANDINO, M. A Formação Continuada de Professores em Ensino de Ciências: problemática, desafios e estratégias. In: Magistério, Construção Cotidiana. CANDAU, V. M. (org.). 2 ed. Petrópolis: Vozes, 1997.

MOREIRA, M.A. A teoria dos campos conceituais de Vergnaud, o ensino de ciências e a pesquisa nesta área. Investigações em Ensino de Ciências, v.7, n.1, 2002.

MUNFORD, D; LIMA, M.E.C.C. Ensinar ciências por investigação: em quê estamos de acordo? Revista Ensaio, Belo Horizonte, v.9 n.1, 2007. 
NRC - National Research Council (2000). Inquiry and the National Science Standards: A guide for teaching and learning. New York, National Academy Press.

ROSA, M.I.F.P.S., et al. Formação de professores da área de Ciências sob a perspectiva da investigação-ação. Revista da ABRAPEC, 3(1): 58-69, 2003.

SÁ, E.F; PAULA, H.F.; LIMA, M.E.C.C.; AGUIAR, O.G. As características das atividades investigativas segundo tutores e coordenadores de um curso de especialização em ensino de Ciências. VI ENPEC, 2007.

SÁ. E.F. Discurso de professores sobre ensino de ciências por investigação. 2009. Dissertação (mestrado em Educação) Faculdade de Educação - UFMG, Minas Gerais.

SANTAROSA, L.M.C. Formação de professores a distância e em serviço através de ambientes digitais - a vivência do proinesp. Novas Tecnologias CINTED-UFRGS na Educação. v.3, n.2, Novembro, 2005.

SANTOS, W.L.P., et al. Formação de professores: Uma proposta de pesquisa a partir da reflexão sobre a prática docente. Revista Ensaio, Belo Horizonte, v.8, n.1, 2006,

SOUSA, C.M.S.G.; FÁVERO, M.H. Análise de uma situação de resolução de problemas de Física, em situação de interlocução entre um especialista e um novato, à luz da teoria dos campos conceituais de Vergnaud. Investigações em Ensino de Ciências, v.7(1), p.55-75, 2002.

TAMIR, P. Pratical Work in school: an analysis of current pratic, In: WOOLBOUGH, BRIAN (ED), Pratical Science. Milton Keynes: Open University Press, 1990.

TARDIF, M. Saberes Docentes e Formação Profissional. Petrópolis: Rio de Janeiro. Editora Vozes, 2002.

VERGNAUD, G. La Théorie des champs conceptuels. Recherches em Didactique des Mathématiques, v.10, n.23, 133-170p., 1990. 